Österreichische Akademie der Wissenschaften / Austrian Academy of Sciences AAS WORKING PAPERS IN SOCIAL ANTHROPOLOGY Volume 30

Lena Springer SAFEGUARDING CHINESE MATERIA MEDICA: ONE FAMILY AS A CASE OF TRANSMITTING TRANS-REGIONAL PHARMA-CRAFT, AND SCHOLARLY
SCIENCE IN CONTEMPORARY CHINA

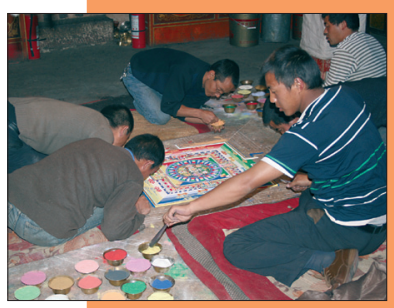




\section{AAS Working Papers in Social Anthropology / \\ ÖAW Arbeitspapiere zur Sozialanthropologie}

ISBN-Online: 978-3-7001-7905-4

DOI:10.1553/wpsa30

Wien 2016

\section{Editors / Herausgeber:}

Andre Gingrich \& Guntram Hazod

(C) Institut für Sozialanthropologie

Österreichische Akademie der Wissenschaften

Apostelgasse 23

A-1030 Wien

Fax: 01/ 51581-6450

E-Mail: sozialanthropologie@oeaw.ac.at 


\title{
SAFEGUARDING CHINESE MATERIA MEDICA: ONE FAMILY AS A CASE OF TRANSMITTING TRANS- REGIONAL PHARMA-CRAFT, AND SCHOLARLY SCIENCE IN CONTEMPORARY CHINA
}

\author{
LENA SpRINGer
}

\section{Introduction}

Chinese medicine is a faceted field, both multi-disciplinary in academia, and multi-occupational in the praxis and education of medical treatments. Basic tasks that specialised personnel need to solve include the supply of medicinal drugs and materials, and tackling the multi-ethnic circulation of Chinese materia medica. 'Chinese medicine and pharmacy', as this field is frequently called in Chinese, involves the physicians prescribing the ingredients of a formula, and also the constructors and circulators of the ingredients. The pharmaceutical side of Chinese medical culture is the crux of this paper - especially the puzzle of how to best transmit crucial knowledge about the ingredients in a Chinese medical formula. ${ }^{1}$

In present-day China, Chinese materia medica brings together scholars and craftsmen from distinct academic, ethnic and family backgrounds who circulate drugs, and also education about their reliable names and properties. Ethnographic fieldwork shows that refined Chinese medical formulae and delicate processing techniques constitute material cultural domains that correspond to the modern scientific distinction between medicine versus pharmacy. Yet together formulae composition and processing knowhow allow the suppliers, local physicians, and particular academic researchers to enact the construction of medicinal drugs per se and to ensure the continuous flow of transmitted knowledge about them. Here, various artisans, scholars, and scientists negotiate: Where do these medicinal drugs and materials belong? Whom do they identify as their source? Names of a drug may indicate its properties in different languages - of the 55 official minority nationalities for instance, or of sciences such as botany or pharmacy which have their different standards and reference works for scientific names and taxonomy. Moreover, specific personnel can transform drugs in specific ways, and define the materia medica in their own words. Thus, drugs in the making reveal stages of production and processes of naming in numerous sub-fields of materia medica studies.

Below, one family serves as an example of how to run a Chinese pharmacy. It is one of the classic Chinese pharmacies ${ }^{2}$ : set in a context of small-scale to large-business, of informal to licensed practice, and of unregulated and official education. In a wide-spread scholarly endeavour, and at

\footnotetext{
${ }^{1}$ The author presented a previous version of this paper as an International Guest Lecture at the Institute for Social Anthropology (ISA) on October 15, 2015 with the title 'Ethnographies of Trans-Regional Pharma-craft and Science in Contemporary China: One Family as a Case of Encounters between Suppliers of Crude Medicinals, and Refiners of Distinct Formulae'. Research presented in this working paper will be part of the author's contribution as Wellcome Trust Research Fellow to the collaborative project "Beyond tradition: Ways of knowing and styles of practice in East Asian medicines, 1000 to the present" at University of Westminster, London.

${ }^{2}$ For images of the surprisingly unchanging equipment and furniture of a Chinese pharmacy, see the catalogue of Paul U. Unschuld's exhibition 2007 of pharmacy furniture from his collection, a photo of
} 
local workplaces, very different experts need to work together to supply and prescribe Chinese drugs. The framework of Chinese materia medica prevails based on their joined efforts and esteemed lingua franca - in spite of the scattered records and multi-ethnic exchange of medicinals.

The case of one family provides a mosaic of unofficial histories about transmitting Chinese materia medica. The various family members deal with their own lives - each of them involved in various ways of acquiring, applying and spreading the knowledge about Chinese drugs -, and thus they tackle broader Asian regional historiographies. Situated in the southwest of China, the parents' clinic is actively involved in medical cultural relations that - as viewed from a wider regional perspective - connect to Southeast, South and Central Asia. In the national capital Beijing, their son is employed as an academician. He represents China's science in international academic relations by handling medical cultural heritage preservation in conversations with the United Nations, but also on a national scale by dealing with heritage historiography within politically layered mainland China. The particular case of this family also illustrates sociocultural mobility in lineages from one generation to the next. Taiwan is the current home of the daughter's life and career, and here the historical influence on healthcare by Japanese colonialists and by Taiwan's nationalist government have a direct impact on her situation today and plans for the future. In a nutshell, the particular Chinese mainland history of institution-building is not recognised in Taiwan or Japan; as a consequence, just like generally among many nation-states, her graduation from university or her vocational certificate from the mainland are hardly transferred from one country to the other.

My argument in this paper is twofold. Through the lens of kinship, I aim to show that craft and science are both crucial for enhancing the transmission of the continued yet changing Chinese materia medica. This thesis about informal transmission of techniques, and officially recognised knowledge about them discloses a second aspect: the roles played by experts other than physicians. I aim to show why Chinese materia medica is transformed and transmitted by a number of personnel and institutions whose work and education are not restricted to medicine in a narrow sense.

For this purpose, I will go through Chinese terms for kinship that tackle the preservation of heritage and the related practicalities of kinship. The merits of ethnographic fieldwork are decisive to examine local workplaces and kinship relations of apprenticeships; ethnographies can reveal oral histories in local context of practice, and in trans-local ritual contexts of kinship and scholarship. Such kinship in the field is not the same as or even accessible in current formal records or official regulations only. On the other hand, I have come to accept during my fieldwork over a decade that in any attempt to safeguard Chinese materia medica knowledge as encountered in the field, the state and specific official institutions in China can hardly be eschewed. Official regulations and institutions circumscribe kinship not only in family law, for instance, regulating directly mostly patrilineal kinship or affinal kinship through marriage, but they also determine kinship in other kinds of lineages. Whether or not an informal relation between master and disciple will be recognised as her or his apprenticeship or as a person's educational background for the transmission of Chinese medicine or materia medica, depends on diplomas, certificates and licenses. The process of tracing such heritage relations is ongoing. The kinship relationships in materia medica are subject to official regulations on the many levels of government, recognised according to the coexisting regimes of

a present-day Chinese pharmacy, and one from the early twentieth century. For additional photos about such Chinese pharmacies and the various pharmaceutical products exhibited there in Shanghai, see Zhang et al. 2014. 
the UNESCO and an independent regime within China. Between one and the next generation of physicians or materia medica artisans, different occupational hierarchies and academic curricula distinguish the opportunity structure for recognised transmission, i.e. certification of one's next biographical step of formal education. Chinese medicine and materia medica knowledge, just as generally kinship in China, are enacted in relations that anthropologists can access via fieldwork, but that we can additionally study in the socio-cultural history of economy and science. Social anthropology has a long history of debate about kinship and the state in China, and the role of writing next to oral cultural transmission deserves further investigation.

Neither written archives nor ethnographic fieldwork alone suffice to reveal how Chinese medicine and materia medica are transmitted. I will argue that a broader and more comprehensive grasp of Chinese medicine reveals the roles of knowledge holders that are versed in different kinds Chinese drugs of the same set in a well-equipped Chinese pharmacy. Often they are not only physicians but - beyond academic degrees in Chinese medicine, and prior to the final standard prescriptions - also pharmacists. This more inclusive perspective on Chinese medicine elucidates the importance of kinship that is involved in the transmission of knowledge about Chinese materia medica. Besides family connections and the transmission from masters to apprentices, kinship in a general sense also includes the institutional background of the 'state' in China, such as cohorts of university graduates, and lineages of academicians and intellectuals. How occupational-disciplinary encounters play out in such kinship relations can be illustrated by the parents' clinic/pharmacy, the son's task as an academician, and the daughter's situation in Taiwan. Family lineages link to scholarly currents and institutionalised education. Additionally, I shall introduce the other staff who are employed by the parents. For that web of lineages converging in one clinic/pharmacy, vocational education is just as crucial as academic education. Hometown relations, too, inform the family's search for staff and their own vocational education of staff about Chinese drugs versus state-orchestrated vocational education.

\section{Kinship}

How to best transmit Chinese medicine? Who personifies my next or my previous generation in a lineage of transmission? Usually the next generation (houdai 後代) are family members, preferably patrilineage. However, as the case of this family illustrates, they also include daughters. Mothers may play just as influential roles as fathers in the 'interdependency' of family decisions. ${ }^{3}$ What is more, also hometown relations prevail in spite of the fact that this family, for example, is spread across occupations, disciplines and shifting political territories. To continue running our family's clinic and pharmacy, what personnel do we need to staff that shop, and how can we plan ahead for that education and ensure the future of our small-scale family business? These are some of the questions that the senior couple of by now grandparents are dealing with who run a Chinese medical clinic/pharmacy in picturesque tree-covered and ethnically just as botanically rich Guizhou Province (Guizhou sheng 貴州省) today.

What are the advantageous careers for my next kin who like myself practice Chinese medicine, yet in a different town, changing time and society? Both children, a son and a daughter, studied

\footnotetext{
${ }^{3}$ On the intergenerational interdependence, and the active role of the senior generation of the grandparents in family decisions, see Liu 2014.
} 
Chinese medicine and pharmacy (zhongyi 中醫, and zhongyao 中藥, respectively) in the capital Beijing. My first encounter with them in 2005 happened when I was carrying out a series of narrative-biographical interviews there, aiming to introduce senior Chinese medicine practitioners and their take on the history of institutionalisation and revolution of (Chinese medicine in) twentieth-century China. Since then I am beginning to grasp how the various family members carry on with their individual lives and careers, and how they cultivate lineages of transmission (chuancheng 傅承) among themselves and beyond. Fieldwork and unofficial historiographies promised to open up the access to easily overlooked, rarely studied and under-theorised facets based on the father's version of historiography. Upon the encouragement and invitation of his children (today also parents themselves) in Beijing, I decided to travel to Guizhou in 2005 to interview the father (who is now grandfather) and also observe the situation at his clinic. It became clear to me very soon that in China transmitting medical culture and practice required safeguarding more broadly a range of knowledge, and more comprehensively ethno-economic branches.

Kinship in China falls under two Chinese terms about lineages: lineages in a patrilineal family (jiazu 家族), and on the other hand lineages in currents or schools of scholars, physicians or artisans (xиерai 學派 or liupai 流派). ${ }^{4}$ The fine differences between family lineages and scholarly or artisan lineages can be decisive when it comes to "lawfare", ${ }^{5}$ i.e. claims for formal recognition such as legal decisions about the recognition of a series of generations of master-disciple relationships as a basis for recognised intangible cultural heritage (fei wuzhi wenhua yichan 非物 質文化遺產). ${ }^{6}$ Family is still an ideal of patrilineal transmission adhered to, yet it is not the only option and adopting sons (or daughters) as part of one's family lineage has a long history in China. The boundary between a family lineage of transmission and a scholarly, medical or artisan lineage is permeable. Vice versa, artisan or scholarly currents also have features of family lineages. In the case of this family for instance, if the son and daughter - who have by now already started their own families and careers elsewhere, i.e. in Taiwan and in Beijing, will not return to Kaili and run their parents' business, two members of staff can take over that role based on their many years of training under the father's guidance. That artisan lineage relation is further fostered and legally confirmed by vocational exams (zhong(deng)zhuan(ye xuexiao) 中等 專業學校, and dazhuan大專) and certificates of professional status (zhiye zige 執業資格) that I have had a chance to look at and discuss in much detail. Whereas scholarly and artisan lineages are nowadays influenced by the official recognition of academic degrees and vocational diplomas, still they involve rituals and behaviour - towards one's doctoral supervisor, scholarly teacher or master of craft - that are very different from the rather loose relations in Europe, to one's doctoral supervisor for instance. Support networks among old boys' groups of graduation cohorts (tongban tongxue 同班同學) are as strong in China at least as in Europe. Belonging to a

\footnotetext{
${ }^{4}$ On 'currents' in Chinese medical history, see Scheid 2009 work on the Menghe medical current.

${ }^{5}$ Cf. Comaroff and Comaroff 2009: 52-59.

${ }^{6}$ When I last enquired, five generations were necessary for an artisan or medical lineage to be considered for starting the application process for inclusion into the intangible cultural heritage. This is the same for wooden combs and wooden architecture that I investigated in Jiangsu Province (Jiangsu sheng 江蘇省) as for Chinese or nationality medical lineages.
} 
family/vocational lineage of Chinese medicine and pharmacy as the one that this article introduces manifests a closer bond than just educational cohorts.

In the small-scale family business, histories of lineages are at stake that continue currents of scholarship and craft and that extend into Chinese medical literature just as into local ethnic and into trans-regional rural industry. Both informally and officially, the multi-ethnic materia medica here in southwest China and Guizhou especially is present in the day to day running of the clinic and in memories of the family since the great-grandfather had settled here fleeing from the Japanese military invasion of China. I travelled to Kaili city (Kaili shi 凱里市) for the first time later in 2005 to carry out the interviews with the father - Zhou Wenyuan 周文遠 - and his wife, by now in 2016 already grandfather and grandmother of five grandchildren. The city is the capital of Qiandong Autonomous Prefecture of the Miao Nationality and Dong Nationality (Qiandong miaozu dongzu zizhizhou 黔東苗族侗族自治州). The parents remember - after they had been sent home due to their then despised class background to work in the countryside in neighbouring Jiangxi Province (Jiangxi sheng 江西省) in the 1960s - they arrived again in Kaili in the 1970s as barefoot doctors (chijiao yisheng 赤腳醫生) working in the first health station (weishengyuan 衛生院) in town. That was newly established from scratch. It was then that roads were built for the first time through the landscape of numerous little peaks of hills covered in forest. Today the city is a tourism destination and connected by fast train (gaotie 高鐵) to the national capital Beijing and neighbouring southwestern provincial capital Kunming (昆明). Most of the patients in the family's clinic/pharmacy today (in 2005 just as in 2015) are still Miao, Dong or Yao - today three fields of increasingly recognised 'nationality medicine and pharmacy' (minzu yiyao 民族醫藥). On the local weekend market, suppliers market their ethnicity next to the exhibited classic red textile banners with expressions of personal gratitude by patients, and exhibited fake patents for nationality drugs. Thus, the ethnic medicinal resources have become a cultural industrial commodity that suppliers even in the informal sector advertise by self-made signs of masterly and formal legal authority and by claiming ownership of intellectual property.

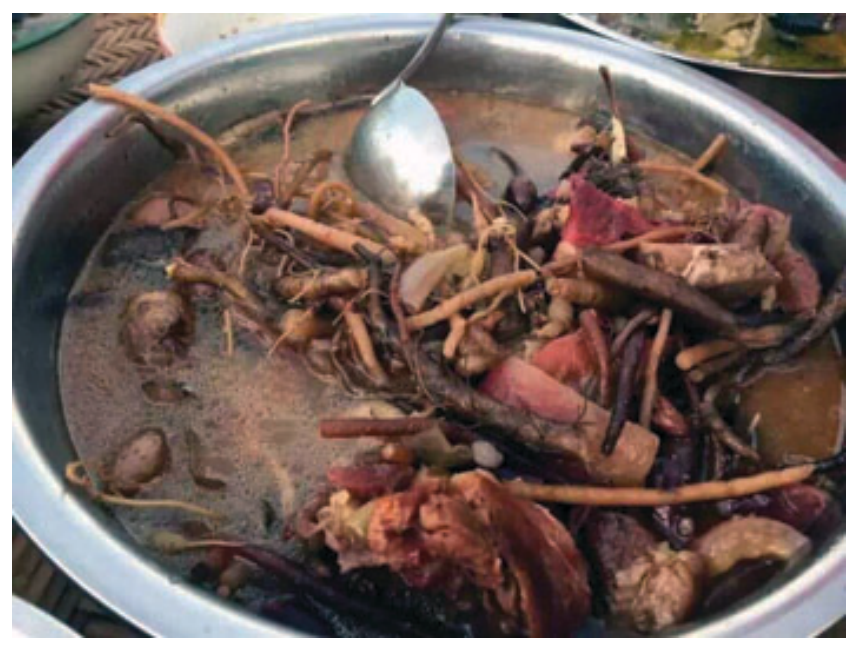

Fig. 1.

Chinese medical soup.

(Photo: L. Springer)

At the same time, some of the nationality practitioners pursue careers as officially certified 'famous senior Chinese medicine physician' (minglao zhongyi 名老中醫) and even leaders of hospital departments specialising in Chinese just as nationality medicine. While other cultural backgrounds of materia medica deserve further investigation just as much as this multi-ethnic 
and multi-occupational situation, I recall my first encounter of the sheer vastness of Chinese and nationality medical culture in a rather material and practical way. When I had just arrived on a long bus journey, the family took me to try the local street food of soup that should prevent me from catching a cold. On sticks I could choose various mushrooms and herbs from the region and add them to my soup. What is going on in the minds and praxis of formulating mixtures of medicinals in this family who are university-educated and versed in the scholarly scripts of Chinese medicine, yet treat patients in a town where local 'ethnic' materia medica is available, too, and useful for some of their experimental adaptations of formulae? That puzzle shall introduce the family and how they are dealing with transmission: of Chinese medicine and materia medica knowledge and skills.

\section{Puzzle of the soup (pharmaceutical decoction tang 湯)}

A puzzle illustrating the concrete experience and practical handling of Chinese materia medica is the pharmaceutical decoction or soup (tang 湯). This boil of steaming liquid with its strong smell and time-consuming preparation process is also prominent as a symbol and target of the iconoclasm and ridicule that Chinese drugs still constitute today in popular discourse and all sorts of debate about China and its development. ${ }^{7}$ Upon discussing the regulation, future development, scientification, and rural industries, that pharmaceutical mixture or decoction remains the obstacle and a material cultural contact zone that various negotiators of Chinese materia medica confront. Who are the crucial workforce to ensure reliable knowledge about the ingredients? Once we take that political challenge seriously, the second facet of that souppuzzle is connectivity and circulation: How can the distinct involved actors in China's changing society collaborate and find common languages to ensure the supply and quality control of 'Chinese medicinal drugs' (zhongyi-yao 中醫藥)? Chinese materia medica are highly fragmented domain and pointing out its cultural complexity and ethnic plurality is a rather straightforward task, yet the long history and vast scale of drug trade, and informal scholarship as well as official regulation even in modern times provide for continuities of materia medica in China. Along the silk road, traders circulated drugs since the Tang dynasty (618-907); the first official compilation of materia medica was compiled also in the Tang dynasty, and continued sociocultural history of circulating printed and manuscript textual reference works refers back to the Song dynasty (960-1279) when imperial regulative impact on pharmacy occurred in a context of empiricism and historiographical-philological debate. The actual drugs and materials may or may not be the same over such a long period of time. Still in the Chinese case the coexistence of artisanal, scholarly and scientific knowledge about a Chinese medicinal is extraordinary. The extent is high to which ancient scripts and earlier modern debates are still accessible for suppliers and highly skilled Chinese medicine prescribers and suppliers, and also the extent is high of how relevant these earlier studies are to the practicalities of current supply and more recent studies on materia medica.

Medicinals in China are on the one hand just crude substances that may be turned into scientific pharmaceuticals, into traditional Chinese medicine (TCM), or into "minority"

\footnotetext{
${ }^{7}$ On modern pharmaceutical and materia medica history, see Andrews 2014, and Lei 2014, on the impact of historical formulae in modern times, see also Karchmer 2013, on regional medicines and the genres of formularies and materia medica, see Hanson 2013.
} 
medicines. The latter tend to be classified according to the "minority nationalities" (shaoshu minzu 少數民族) of 1950s Maoist China (Mullaney 2011). Labels of products, however, increasingly contradict those official ethnic classifications. ${ }^{8}$ As a consequence, various artisans, scholars and scientists negotiate: Where do these medicinal drugs and materials belong and whom do they identify $?^{9}$ In Chinese language, 'materia medica' (bencao 本草) are a multidisciplinary domain of studies on ancient to the latest state-of the-art texts listing and compiling updated entries medicinal things (yaowu 藥物) and materials (yaocai 藥材) that include parts of plants, animal products, minerals and even metal ingredients. Studies in this diverse genre include philological studies on the correct names and properties of medicinals just as written-down oral knowledge and reprinted manuscripts about the best mixtures of ingredients in formulae for certain illnesses and origins of high quality drugs. The overlap with pharmacy and botany is close as early official compilations and reference works of Chinese materia medica since the late twentieth/early twentieth century mix philological reference with terminology from pharmaceutical legal codes, botanical nomenclature and morphology, and vernacular names of drugs and places next to chemical scientific formulae. ${ }^{10}$ 'Chinese medicinals' (zhongyao 中藥, or 'Chinese medicine-drugs' zhongyi-yao 中醫藥) range from raw materials as well as ready-made pharmaceutical products to entries in journal articles about materia medica or in regulative publications; physicians prescribe them and apothecaries sell them as particularly Chinese medicines. Medical history has it that Chinese 'materia medica' were plant-based to a large extent in clinical practice but that the word names a medicinal part (i.e. the root) in the first Chinese character plus as the second character plants (i.e. grasses or herbs) as placeholders representing, firstly, the other kinds of parts as well plus, secondly, those other main categories of ingredients (incl. animals, minerals, metals). Instead of herbs, the soup (or decoction) is the main feature that goes back to the early discovery of the necessary fundamental technology (Wu 2007: 20ff., 17f.).

\section{Pharmacraft, and science (thesis-1)}

How occupational encounters play out in the family's relations and envisioned developments involves both the practicalities of handling materia medica, and constant adjustments of the occupational status of pharmacraft to the newest regulations. ${ }^{11}$ Manufacture (jiagong 加工) is a central theme in conversations of Chinese medicine physicians and unlicensed prescribers that I have overheard at various sites during ethnographic fieldwork. The father (and grandfather)

\footnotetext{
${ }^{8}$ On the case of Tibetan and Chinese medicinals in Sichuan province, see Springer 2015.

${ }^{9}$ Farquhar and Lai 2015 discuss the emergent official institutional order of and the informal role of healing establishing nationality medicines.

${ }^{10}$ On manuscripts and on complexities of the Ming dynasty's materia medica compilation that has been and continues to be celebrated in modern pharmaceutical science, see Unschuld and Zheng 2012, 2014. My favourite example is Zhao Yühuang's 趙燏黃 (1883-1960) work who studied botany and pharmacy in Japan and taught it in China pioneering materia medica studies that combine what he called 'old' and 'new' materia medica, i.e. ancient Chinese texts and modern texts including chemical formulae, scientific botanical names, photos from morphological plant studies and plants in stages of artisan processing.

${ }^{11}$ On the precarious situation of suppliers in southwest China who collect medicinal materials for the food and wellness market, and the obscuring naming and labelling of wellness and medicinal products from China, see Tsing 2015.
} 
in this family develops strategies of legitimising and improving professional status both with junior members of his next generation, and with his staff who take care of the day-to-day running of his apothecary. The clinic/pharmacy has a front section next to the main entrance to the street; that is where patients pick up numbers in the morning, wait and where they finally purchase the drugs that all day long staff pick out of the meters-long traditional wooden medicine cabinet, measure and wrap up in paper as portions for decoctions that the patients will brew one by one at home. Through a wooden wall with glass windows the waiting patients may peek into the next section, the room were the father diagnoses the pulse, tongue and the conversation with his patients and writes down the formulae that patients take back to the staff in the front section. Further backwards are other rooms including shelves for the formal records of each patient's formulae and the numerous plastic bags of registered Chinese medicinal ingredients. The most senior member of staff is most familiar with processing (paozhi 炮製) the medicinals since he used to carry out a major portion of the processing himself on his own when he began working in the clinic/pharmacy in the 1980s. In 2014, when I visited again after nearly ten years had passed by, the father decides to bring that experienced artisan together with his other staff of apothecaries and prescribers for me to a special event to demonstrate the process of manufacture and the tools that had been used in the beginning during earlier years of the clinic/pharmacy. For the junior members of staff this is a unique opportunity to observe the whole process of manufacture as they deal mostly with preprocessed medicinals (yinpian 飲片) and therefore do not know how to carry out the whole procedure of processing from scratch, buying the materials and administering them step by step in one's pharmacy. Processing has been outsourced over the years to selected trusted suppliers in the 'pharma-capital' (yaodu 藥都) Anguo (安國) and in Chengdu (成都).

Jack Goody has shown in his detailed investigation of oral transmission that - under the impact of writing-literature coexisting with the oral genres - narratives may gain authority (Goody 2010). What is disregarded as fiction and just tales (even merely childish fairy tales) in oral or ritual transmission, gained - due to the emergence of written genres - properties of non-fiction and of knowledge worth reciting, and deserves teaching as a set. Accordingly, upon my visit and the opportunity of contributing to written history of their family business and the various involved lineages, the artisan knowhow apparently has become worth demonstrating and transmitting. Once I had been handed a reliable camera to take photographs carefully, the staff laid out bundles of a stored and dried and thus pre-processed Chinese medicinal (yinpian 飲片, lit. a slice [to be prepared for] drinking). To provide a complete picture of the processing, they pulled out the tools that had been used previously (before the collaboration with the trusted suppliers in other provinces and cities began). They included the rusty large-sized and strong cutting knife, a device to crush hard medicinals and turn them into fine powder (by standing on a wheel and moving it backwards and forwards over the medicinals), and pans of the right metal to roast specific medicinals - using them reveals the appropriate qualia of oiliness and transforming yellow colour of the roasted medicinal. The manufacture of pellets (balls wan 丸) by hand impressed the junior members of staff since they had so far seen only the latest electrical machine being used that produces standard-sized pills. Science is relevant here yet in the background as the force and criterion of measurement behind advanced technology. Rather than the botanical or pharmaceutical name Astralagus radix 
of the medicinal, the father and his staff use the established name of the Chinese medical drug in China (huangqi 黃芪, also 黃耆). This is neither a vernacular name nor a local ethnic nationality name. Nor is it for example the name for that medicinal in Tibetan medical culture - also a realm of materia medica terminology on a transnational scale and in contemporary China that suppliers refer to in the region of southwest China.
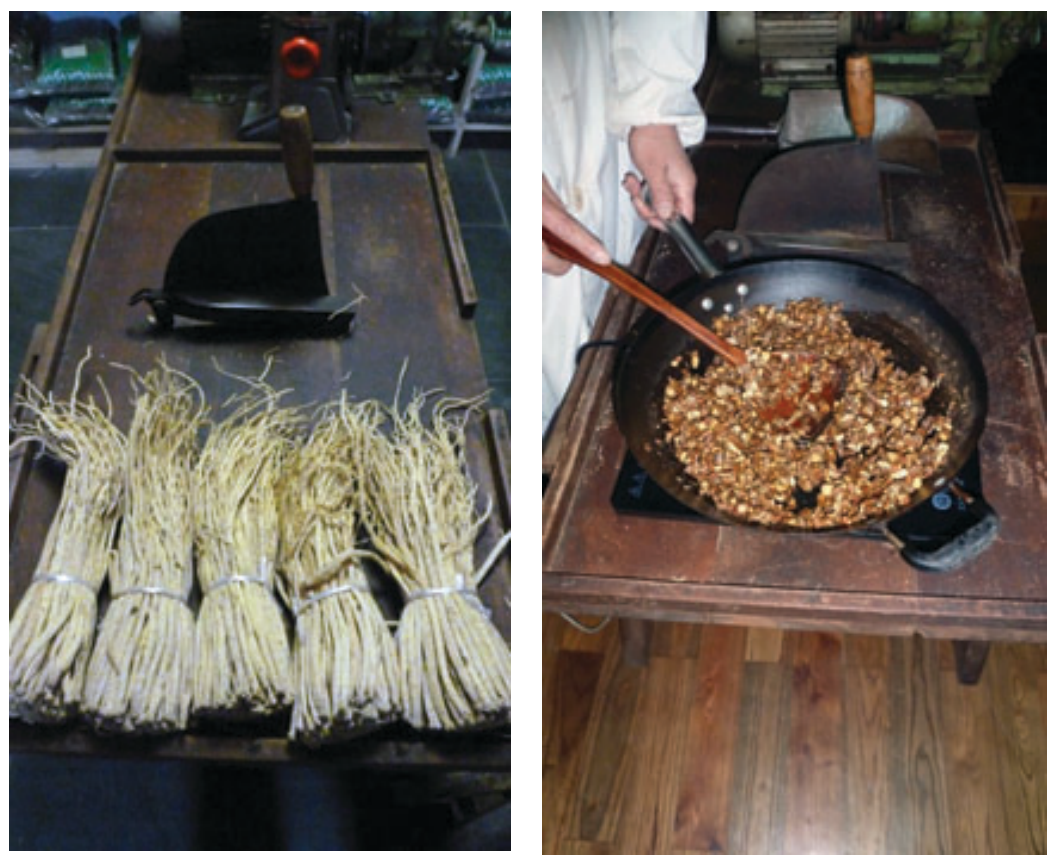

Fig. 2, 3 .

Cutting tool and pan for

huangqi processing.

(Photo: L. Springer)

Science is present directly in this situation insofar as concerns about the recently shifting status quo of legal and illegal forms of processing worry the parents. The trade of pellets might be illegal. During fieldwork in Shanghai a few months later, a university instructor of processing at Shanghai University of Chinese Medicine and Pharmacy had criticised forms of measurement and processing such as pellets since scientific portions according to 'fixed measurements' (dingliang 定量) were the legal standard throughout the entire nation-state: Patients in Shanghai at a hospital will actually frequently buy little plastic bags of standardsized portions of ingredients - to put open them at home and put them into their daily portions of decoction. The academic lecturer doubted that anywhere in the country pellets could still be legal. To give another example, in the Tibetan highlands of Sichuan Province, a senior retired physician from Heilongjiang kept her preferred standard prescriptions, large-sized balls with honey, secret and hesitated to let me photograph these hand-made, most needed and frequently taken drugs. Not an issue at all here are international trade conventions such as CITES about the international export of endangered species. Once the clinic/pharmacy has their set of frequently prescribed medicinals ready, all legally purchased, the concern here is just the way how the formulae is assembled and handed over to the patient. Moreover, some of the processing techniques are deemed so scientifically important that regulators of cultural heritage claim they are state secrets and may not be taught for non-Chinese - such as potentially myself. Clearly my oral interactions during fieldwork are not necessarily resembling "the" situation of written regulations in China. Still, the oral and written genres correlate and in conversations with me practitioners in the field just as regulators governing the written archive 
of rules constantly refer from one facet (informal, non-institutionalised) to the other (official, formalised).

Transmission of Chinese medicine: This question stems from a field of contestation that is dominated by iconoclasm, and - ongoing over more than a century - passionate dispute about a reified traditional Chinese medicine (TCM) (Taylor 2005). It serves as a cultural monolith that seems to manifest national heritage as an artefact ready for exhibition in museums or marketing and export of products for pharmaceutical trade. At the same time, it also resurfaces as one of the esteemed miraculous future innovations and biotechnological developments of China. Safeguarding Chinese medicine is a proclaimed state-project and part of nationbuilding in China. A shared point of reference and interaction of pharmacraft and science in this complex project are the qualia. Colours, temperature, smell, texture, oiliness, metal materiality of the manufacturing tools: University-educated scientists, decade after decade in modern Chinese academia and administration, attempt to collect from and mirror this (oral, unofficial, even anecdotal) knowhow back to the population via written genres of well-ordered education. Tracing such a process requires philological investigation. In the context of the history of science, the laboratory experiment has close linkages to the technology and equipment of the kitchen. Preparing animal parts for daily consumption, or for scientific experimentation, has a history of doubts and disregard in the eyes of science-planners and the public understanding of science. ${ }^{12}$ Here in the Chinese medical clinic/pharmacy, too, the everyday familiarity of artisan equipment and materials and transformations raised concerns about the blurred demarcation of scientific technology and artisan craft.

\section{Medicine and pharmacy: Encounters between suppliers of crude medicinals, and refiners of distinct formulae (thesis-2)}

Many of the various actors in the field of Chinese medicine in contemporary China are not physicians or Chinese medicine practitioners in a narrow sense, but they work within the broader field of 'Chinese medicine and pharmacy' and carry out particular roles: just as textual scholars, as pharmaceutical scientists, as small-scale businessmen, as manufacturers, or as kinsmen supporting the running of a clinic. Among them, even those who have achieved a status as licensed prescribers of certified Chinese drugs or who are graduates of tertiary education in Chinese medicine, would still need to achieve the position of physician at a specific hospital or join or establish a clinic. Easily overlooked from a physician-centred vantage point, supply of medicinal drugs is a basic requirement for anyone running a Chinese clinic. On a national and trans-regional scale, the personnel carrying out and planning supply, or possibly ensuring it for the future, need to include artisans as well as those versed in the relevant ancient-to-modern textual and oral history of medicine and the Chinese materia medica.

\section{1 Kinship interdependence, and personal paths}

Biographical approaches disclose unofficial historiographies and relations in lineages that are part neither of written histories nor of official regulations of careers and occupational roles. The way how decisions are made can be accessed via an individual's life; the threads of inter-

\footnotetext{
${ }^{12}$ On the history of disregard against the kitchen-like tools and procedures in laboratory science, see Guerrini 2016.
} 
dependence around each ego become visible that lead to decisions by, and about or together with, him or her in the first place. For the lineages in a family like the one portrayed here, a model path of personal development lingers in the subtext of many decisions in the family members' biographies. Furthermore, the shared goal of social upwards mobility, too, is a second driving force behind decisions at turning points in individual lives. Firstly, at an early stage of their career, both the staff and the ideal Chinese medicine physician, i.e. the father, mother, daughter and son, learn Chinese medicine and materia medica from scratch for two to three years. That means walking around in the area, familiarising oneself with the, mostly plant, medicinals in their natural habitat and in the socioeconomic webs of supply. This education phase also includes judging the qualities and properties of medicinals according to their look, by smelling and tasting, and throughout series of stages of manufacture and processing. Once that educational step has been accomplished, it is clear for all members of the family and staff in this clinic/pharmacy, fulfilling the role of prescribing formulae is the next step, i.e. not another person's occupational life and role but just the following phase. Later on in the history of the business in China and the biographies of its members, tasks were increasingly separated and collecting, storage, processing that the parents had carried out completely themselves in the early years of their praxis was outsourced or delegated to the staff they could now employ. The academic demarcations between medicine and pharmacy, science and craft, therefore are also expressions of a later phase or high degree in and individual's education in Chinese medicine and materia medica. Starting from the basics, in an historical development of medical academic institutions, or as a generalist starting her or his clinic/pharmacy, separating tasks between an increasing number of employees and business partners and vocational spheres leads on to academic disciplines that specialise and my not comprehend each other's technological skills anymore. Thus, the tasks in this family business illustrate at one site how the scale of Chinese materia medica functions at a locality in response to the regional botanical and ethnic environment and with an esteemed increasing number of vocational staff. Furthermore, we will see below that the family's own children are not the support staff and might even not stay with the role of physician prescribing formulae. Mobile socially and spatial, they have moved on to more scientific and scholarly work.

\section{2 Marriage and skilled insight (daughter)}

The daughter Zhou Lu 周强 is the first child and 'next generation' of her father's (and mother's) medical lineage. The mother Nie Chenqiu's 聶晨秋 family originates from neighbouring Jiangxi Province just like the father's. Her family was active in the running of pharmacies and pharmaceutical trade there. In the 1970s she acquired materia medica knowhow by collecting and processing plants in the Kali area, treating for example women giving birth with acupuncture and managing the growing family business. As a student their daughter moved to the capital Beijing and finished a degree in pharmaceutical science. Already during her studies at university, she returned home regularly to join her father in his clinic and observe his range of patients and his style of treatments, especially gynaecology. During her studies she met her husband and her parents agreed to let her marry into his Chinese medical lineage in Taiwan. Family stories point to encounters with regional materia medica, as the parents moved to the remote mountains in the Southwest, and their daughter to Taiwan. The 
family are to a certain extent integrating them into Chinese medicine formulae: the parents collecting and processing medicinals in the Kaili area and moving on to an increasingly wellsupplied and staffed business; their daughter's contact with her husbands family's usage of Taiwan's materia medica. For this paper one fact is decisive. Having finished her university studies in Chinese pharmacy and back home pregnant with her child, the daughter also passed a professional exam and acquired the certified license to practice as a Chinese medicine physician. Only that certified professional status allows her to run her father's clinic/pharmacy.

Skilled insight into Chinese materia medica is crucial in the ideal early and basic stage of a Chinese medicine physician. Combined with pharmaceutical science of Chinese medicine, as in the case of the daughter, this craft-knowledge overlaps straight with scientific knowledge. Further skilled by her observation of formulae prescription in her father's clinic and later in Taiwan, the daughter has her own understanding of medicinals and of regional variety and responses of different $\mathrm{p}$ atients to the same drugs. When she visits me in Vienna with her whole family in October 2015 and I visit her again in Taiwan in the spring of 2016, we discussed her and her father's clinic and examples of the properties of medicinals. In this paper, let me just pick out one simple observation about all those conversations briefly. Only knowing the different ways of processing the same medicinal allows me to follow on and reconstruct how the patients responded in Kaili and in Taiwan, and how father and daughter respond by modifying their formulae. Thinking this issue further in multi-disciplinary context of materia medica studies the transregional scale of ingredients in formulae and pellets belongs to the field of materia medica studies on the variety ('grades and types' pinzhong 品種) of products. Huangqi that we have encountered in the demonstration event above is a medicinal delicacy when it originates from Mongolia. Looking at the distance and change of landscape on a map, the connection of the family's clinic in Kaili to the supply from there is quite remarkable. Insiders of the pharma-craft and natural-plus-textual science of materia medica discuss ingredients in such trans-regional context and as generalists on a high level they can also link details of processing straight to modifications of formulae. Materia medica studies has sub-fields such as 'grades and types'. It is a special field with its own institutions and editions of reference works. Skilled insights and lives that allow one to acquire both degrees and practical experience are part of expertise in that domain.

\section{3 Materia Medica philology and safeguarding of heritage (son)}

From the perspective of the father's clinic in Kaili, his son is working in "heaven" (tiantang 天 堂). Certainly his scholarly work as an academician at the China Academy of Chinese Medical Sciences (CACMS, zhongyi kexueyuan 中醫科學院) in Beijing is a success for the family and manifestation of upward social mobility - in the history of this family and of the profession Chinese medicine in general. The lineages that the father refers to mockingly as heavenly in a long conversation I heard are scholarly and theoretical rather than applied and concerned with pharma-craft or the ethics and day-to-day practicalities of making one's patients feel better and be healthy again. Due to the increasing social distinctions and cultural historical transitions within Chinese medicine and materia medica in the recent history of (Chinese medicine in) China, a tension has arisen between the son's work in the heaven of officials (guanfang 官方) as opposed to the father's daily work 'among the population' (minjian 民間). 
This tension is a personal biographical and generational development over time, not a private issue. From 5 in the morning to 7 at night the father works in his clinic, 6 days a week, all year long. For his numerous, mostly poor rural, and minority nationality patients and for his staff he accepts a hard life. Like his father he collects books and reads them whenever time allows.

The son thus followed a pattern similar to his sister insofar as he studied Chinese medicine in Beijing, too, and married into a Taiwan lineage of Chinese medicine as well. In addition to that family lineage, the son cultivates two other scholarly ones in his career. At the central academy of science for Chinese medicine he belongs and contributes his research to the Department for Archives of Medical History (yishi wenxian yanjiusuo 醫史文獻研究所). On the one hand his task is to contribute to the safeguarding of Chinese medical heritage by collecting and digitalising medical cultural practices and written archives. He works with his doctoral supervisor and recent head of the department Liu Changhua 柳長華(Liu et al. 2014). On the other hand, he cultivates a scholarly lineage that goes back to Zhang Taiyan 章 太炎(炳麟)(1896-1936), an outstanding figure both in Chinese intellectual and political history and in politically relevant yet classic philological studies of Chinese medical texts.

\section{China anthropology: Does it matter that they are relatives? Does it matter for education how they are related?}

Not merely private details but personal artisan and scholarly relations are crucial for running a Chinese clinic/pharmacy, for transmitting Chinese medicine and materia medica knowledge, and for studies aimed at the safeguarding of that knowledge. This case shows that not just family kinship, not just patrilinear lineages, and not just villages and rural culture separate from a state suffice to explain and to safeguard Chinese materia medica. Neither are overseas nor migrant enclaves that used to be main fields of investigation in the early days of China anthropology certainly today our first access points for investigating everyday culture or religious scholarship.

To indicate why I am underlining correlated kinship and the state here in this way, i.e. private life and family decisions, and official regulations, Maurice Freedman's observation from the 1960s might be helpful (Freedman: 1979: 240-54). He begins

The Western literature on which we draw for much of our knowledge of the family in China is full of variations on the theme that the family was the basic unit of Chinese society. (...) what people usually appear to mean (...) is one of two things: either that the family provided the model for the society as a whole, such that even the total polity might be regarded as one massive family, or that family relationships predominated in their potency over all other kinds of relationship.

To clear the confusion, he found it necessary "to distinguish between family as a specific social group on the one hand and kinship on the other". On the next page, he goes on

Outside his family a Chinese was bound by rights and duties to people related to him through ties of descent and marriage. The relationships traced exclusively and organised as to form patrilineal descent groups. These groups are often referred to in the literature as clans, but it is becoming more common nowadays to give the technically more satisfactory name of lineages (cf. Freedman 1958). 
Rather than tribal clans, and in addition to affinal kinship, Freedman finds 'lineages' also useful to explain kinship relations outside the family. He continues:

Localized lineage where in some parts of the country (especially in the southeast) so wide in their extent that they encompassed large villages and sometimes even towns. [family stout in Scotland fair isle, Look at Life] Almost inevitably, some of their members were rich and others poor. Some might well be scholars, others illiterate.

This is most true in the case of the family introduced above in regards to their hometown and pharmacraft-lineage relations to Jiangxi province where the father's family originates from, and the staff plus their vocational certificates, too. Outside China, closely knit yet socially and spatially widespread families certainly are just as well known, as the legendarily endogamous yet widely emigrating Tyrolians illustrate, or the family Stout in Scotland's Fair Isle that the British ethnography-at-home series of the BBC Look at Life introduced in the 1960s.

Some could move with ease in the wider political society; others were simple countrymen, deprived of influence. Yet lineages are sometimes represented as though they were families. People who make the mistake of thinking of them in this fashion may well be puzzled by the unfamiliar-like behaviour shown by, say, a rich man squeezing his debtor-kinsman or an elder forcing his kinsman-inferior to pay him the deference due to one standing high in the general system of status of the society. A lineage is no family.

Thus, in this family it is worth noticing that members of staff may become the future next generation of the clinic/pharmacy in Kaili. If the university-educated daughter and son will not return back to the little remote southwestern town and tourist-destination but continue their lives in Beijing and Taiwan, the patrilineage in Kaili will be continued by a member of staff once he has passed the necessary vocational exams and has acquired the professional status in the town.

Like I am today, Freedman, too, tried to understand how important kinship was actually as compared to the state. Here is his quote that has kicked of this paper in the first place and that opens up further discussion elsewhere of the stories I have touched upon here.

But let us assume that the problem is to decide what strength of potency lay in kinship relations as a whole. We may take China as it was in the last hundred years of its existence as an imperial state. The question resolves itself into an analysis of how the solidarities and values of kinship were enmeshed in a political and economic order which required of individuals that they owe allegiance to a state and participate, despite the dominance of agriculture, in a wide-ranging economic system.

From the point of view of the state, a man's obligations to it were in fact both qualified and mediated by his kinship relations. They were qualified in the sense that obligations springing from filial piety and mourning duties were held to modify duties owed to the state. (...) For this reason the Code specified the grades and duration of mourning and the ritual costume associated with them.

In the eyes of the state, then, a man stood posed against it in a network of primary kinship duties. But the state also regarded kinship units as part of its system of general control, so that a man's duties to it were mediated through his membership of these units. 
[goes on about Confucian morals] units standing at the base of the social pyramid are expected to control themselves in the interest of the state.

Family lineage (jiazu) and lineage of scholarship (liupai, xиеshu) are closely related, since the son's intellectual task is to safeguard Chinese medicine and materia medica knowledge. However, the official rules for recognition of master-disciple transmission of intangible cultural heritage contradict the specific case of his own family. To acquire the vocational diplomae and professional exams in Kaili, staff and the family's next generation have to go through institutional exams rather than achieve recognition via cultural heritage.

Furthermore, family lineage and officially recognised lineages interweave as the son has a university degree and academic career in mainland China, and as the daughter joined a family business that she used to run according to Taiwan law - where her mainland Chinese university-education or the professional status in Kaili town are not institutionally recognised. In one life of the son and daughter respectively, lineages intermingle that are often studied by separate groups of ethnographers and historians.

As Freedman continued in his classic discussion, the legal context of marriage rights and obligations in China might appear just modern at first sight, yet at a closer look the societal practice of kinship relations become visible. In 1931 the Civil Code that Freedman referred to in the quote above regulated family kinship. That was a new legal development in China. As in imperial times, it was still "a general statement on models of behaviour rather than a body of detailed rules to be closely applied." The practice of law may be "conservative", still, and require new legal models for kinship relations. Freedman illustrates this with a case from 1919 when "purchase of a woman for the explicit purpose of getting children is justifiable and not invalid". Thus, the kinship relations that are wiped out from official records disclose lineages that are most crucial in occupational lives and personal paths.

Jack Goody's (2010) discussion of myth, ritual and the oral also points at the coexistence of formal and informal transmission, of written and oral genres, in rituals of kinship just as in the practice of scholarship. Telling one's life-story as one narrative, as he shows, is by no means a human feature but that happens in response to the written genre coexisting with oral genres. My invitations to tape and photograph the stories of lineages in this family have produced oral and material records that, however, often may not translate directly into official historiographies or into regulated transmission.

\section{Conclusion: Soup and connectivity, family and lineage}

Distinctions matter. In social context, Chinese medicine is actually a 'soup' (tang) of ingredients from materia medica. Ensuring circulation and supply from multiple backgrounds - all the way from raw materials to the decoction in the patient's home - requires transmission of knowledge based both on family kinship the and on artisan or scholarly lineages. From their situated positions in the field of Chinese materia medica, physicians, apothecaries, manufacturers, scholars and scientists accomplish the day-to-day supply of medicinals and thus the running of clinics and pharmacies. In their distinct ways, artisans and academics learn how to deal with regional variation, changing properties and different names of ingredients available in the current market. They distribute situated knowledge about the Chinese drugs 
among clinics and pharmacies, and into academic disciplines and vocational niches that they have established in China's regions in the course of modernisation. 'Connectivity' or 'circulation' (tong) of the materia medica is based on cultivated relations and trans-regional circulation, division of labour and expertise. Thereby, crafts and science converge.

Both craft and science rely on official and informal means of recognition. Assuming an ideal educational model, an artisan physician, e.g. the father in this family, would early on encounter pharmaceutical techniques that ensure reliable supply, and he would learn how the set of ingredients stored in the family's clinic are produced and have different properties. Academic physicians, which the daughter and son have become, may study pharmaceutical techniques in the laboratory or in historical Chinese archives. Thus 'family lineage' (jiazu) and scholarly or artisan 'lineage' (xuepai, liupai) converge in one and the same person' life. Interdependence occurs both in family decisions, for example about marriage or careers, and due to the institutionalised steps of social mobility. The members of this social system illustrate three facets of kinship:

Firstly, father and mother, daughter and son are the core of the family lineage. Affinal kinship extends further to their wives/husbands who both belong to Chinese medicinal/pharmaceutical lineages in Taiwan.

Secondly, artisan lineages and vocational certificates integrate the staff into the web of kinshiplike relations that belong to the clinic which the parents are running.

Thirdly, lineages also include the daughter's official graduation from university in Chinese pharmacy, and the son as a disciple of scholarly masters in textual scholarship and as a contributor to the safeguarding of state heritage.

Finally, this family illustrates the trans-regional scale of pharma-craft and routes of supply and migration. Family members originate from three generations of the clinic and attached pharmacy in Guizhou Province. Earlier generations lived and worked in neighbouring Jiangxi Province. Across these two family backgrounds in two provinces, the parents operate lineages of pharma-craft, and they handle the politics of vocational education and responses to latest regulations of small-scale Chinese clinics/pharmacies. Sichuan and Hebei Provinces are nodes in the parents' supply network through which trusted traders of materia medica are sending off packages of ingredients. The transregional linkage points for the daughter's and the son's households are Taiwan and the national capital Beijing where they have studied, live, work, and send their kids to school. Along these various lineages, the occupational lives safeguard Chinese medicine and transmit know-how about materia medica ingredients.

LENA SPRINGER is an anthropologist and sinologist, currently investigating materia medica studies in modern China as a Jing Brand fellow at the Needham Research Institute in Cambridge. Her book project about how regional suppliers of Chinese materia medica deal with the variation of names and the education of properties contributes to the Wellcome Trust project 'Beyond Tradition' at the University of Westminster's research group 'East Asian Sciences and Traditions in Medicine' where she is an affiliated researcher. A co-edited special issue in Asian Medicine (Brill) introduces histories and ethnographies of efficacy and safety in Tibetan and Chinese medicine. Her forthcoming book recalls modern Chinese history according to the narrated careers of senior Chinese medicine physicians. 


\section{Literature}

Andrews, Bridie. 2014. The Making of Modern Chinese Medicine, 1860-1950. Vancouver: University of British Columbia Press.

Comaroff, John and Jean L. Comaroff. 2009, Ethnicity, Inc. Chicago: University of Chicago Press.

Freedman, Maurice. 1979. The Family in China, Past and Present. Essay 14, The Study of Chinese Society: Essays by Maurice Freedman, selected and introduced by G. William Skinner. Stanford: Stanford University Press, 240-54. (Pacific Affairs, 34(4) (1961), 32336. Repr. in A. Feuerwerker (ed.) 1964. Modern China (Englewood Cliffs, N.J.), 27-40; and in H. Kent Geiger (ed.) 1968. Comparative Perspectives on Marriage and the Family. Boston: Little, Brown \& Co., 12-26.)

Farquhar, Judith and Lai, Lili. 2015. Nationality Medicines in China: Institutional Rationality and Healing Charisma, Comparative Studies in Society and History 57(2): 381-406.

Goody, Jack. 2010. Myth, Ritual and the Oral. Cambridge: Cambridge University Press.

Guerrini, Anita. 2016. The Ghastly Kitchen, History of Science 54(1): 71-91.

Hanson, Marta. 2013. Speaking of Epidemics in Chinese Medicine: Disease and the Geographic Imagination in Late Imperial China. Needham Research Institute Series. London: Routledge.

Karchmer, Eric I. 2013. Ancient Formulas to Strengthen: Healing the Modern Chinese Body with Treatise on Cold Damage, Asian Medicine: Tradition and Modernity 8(2): 394-422.

Lei, Sean Hsiang-lin. 2014. Neither Donkey Nor Horse: Medicine in the Struggle over Chinese Modernity. Chicago: University of Chicago Press)

Liu, Changhua 柳長華 (ed.) 2014. Yidao guanzhu 醫道貫注, Beijing: Zhongyi guji chubanshe, 246-249.

Liu, Jieyu. 2014. Ageing, Migration and Familial Support in Rural China, Geoforum 51: 305312.

Mullaney, Thomas S. 2011, Coming to Terms with the Nation: Ethnic Classification in Modern China. Berkeley: University of California.

Scheid, Volker. 2009. Currents of Tradition in Chinese Medicine, 1626 to 2006. Seattle: Eastland Press.

Springer, Lena. Forthcoming. Collectors, Producers, and Circulators of Tibetan and Chinese Medicines in Sichuan Province, Asian Medicine: Tradition and Modernity 10(1-2).

Taylor, Kim. 2005. Chinese Medicine in Early Communist China, 1945-63: Medicine of Revolution. London: Routledge.

Tsing, Anna L. 2015, The Mushroom at the End of the World: On the Possibility of Life in Capitalist Ruins. Princeton: Princeton University Press.

Unschuld, Paul U. and Zhang, Zhibin. 2014. Introduction, in Dictionary of the Ben cao gang mu Vol. 1: Chinese Historical Illness Terminology. Oakland: University of California Press)

Unschuld, Paul U. and Zheng Jinsheng. 2012. Introductory Essay. Chinese Traditional Healing. The Berlin Collections of Chinese Medical Manuscript Volumes of the 16th through Early 20th Century. Leiden: Brill.

Unschuld, Paul U. 2005. Das Heil der Mitte: Katalog zu einer Ausstellung zur Geschichte und Gegenwart, Theorie und Praxis der Chinesischen Medizin. Nordico-Museum Linz. München: Cygnus Verlag. 
Wu, Hongzhang et al. 吳鴻洲. 2007. A History of Studies on China Medical Formulae and Medicinals (Zhongyi fangyaoxue shi 中醫方藥學史). Shanghai: Chinese Medical University Publishing House.

Zhang, Wenyong 張文勇 et al. 2014. Shanghai Cultural History of Traditional Chinese Medicine (Shanghai zhongyiyao wenhuashi 上海中醫藥文化史. Shanghai: Science and Technology Publishing House. 